\title{
Knowledge, responsibility, decision making and ignorance:
}

\author{
Everyday conduct of life with Huntington's Disease
}

\begin{abstract}
Summary
This article is concerned with the question of how to argue about morality and ethics in relation to a severe and deadly hereditary disease. It is inspired by the uneasiness I have felt on a number of occasions when "right and wrong" is being discussed by persons at risk, professionals and in particular when discussed by outsiders. This task is not an easy one and the article tries to lay out more groundwork than it arrives at conclusions. Below follows a brief introduction to my framework and some of the concepts that are important for my way of outlining the arguments that follow. Then I take a closer look at genetic knowledge, responsibility and decision making, because these seem to be important issues in my field of study. I have added ignorance to the list in order to discuss a further aspect of dealing with hereditary disease. Interestingly, ignorance (understood both as being ignorant of and ignoring) seems to be commonly applicable to describing persons living at risk for Huntington's Disease (HD). So what does everyday conduct of life look like from an "ignorance" perspective? And how can we discuss and argue about morality and ethics taking these seemingly diverse ways of living at risk into account? Posing this question, I hope to contribute to new reflections on possibilities and constraints in people's lives with HD as well as in research and to open up new ways of discussing "right and wrong".
\end{abstract}

\section{A framework}

$\Lambda$ $\mathrm{t}$ present, medical genetics is rapidly bringing about new genetic knowledge while its associated technologies offer new choices between different courses of action. Hence the field of medical genetics prompts persons living at risk of hereditary disease to reflect on their situation and to act in moral accordance with what they know. This moral prompting is not inherent to genetic science or practice as such. It comes about through our understanding of the relation between knowledge and responsible decision making in our part of the world. Namely the former as a solid foundation for the latter. According to this logic, ignorance (in both senses) can be staged as problematic in as far as it limits persons at risk in acting responsibly towards family and offspring. You have to make use of genetic knowledge in order to be living and choosing responsibly. In this article I will discuss the widespread notion of knowledge as true and fixed in order to show that it is not beyond uncertainty, ambiguity and negotiation when used as a basis for responsible decision making. I will argue that the fast changing and situated nature of knowledge and technology 
makes it difficult to maintain that entering the domain of "knowing" assures responsible decision making in a universal or absolute manner. It also makes it difficult to judge ignorance irresponsible per se. Along these lines, attributing universal value to informed decision making can be problematised as staging the possibility for rendering this course of action more responsible than any other and hence of a higher moral or ethical standard. I will end up by arguing that we have to move away from the understanding of ignorance as inherently "wrong" when considering the nature of knowledge and the way responsibility and decision making are enacted in people's everyday lives. Instead we have to engage in people's 1. person perspectives ${ }^{1}$ on their own situated participation in concrete social practice. Doing so, we might be able to say something about how ignorance works in people's lives, for themselves as individuals as well as for their families and relationships. Hence our moral and ethical concerns should be connected to how people navigate through life, taking wider familiar, social and societal implications into account and should not be about creating a set of decontextualised rules to be followed regardless. This does not mean that we can avoid making use of culturally available maps and tools (ethics, norms, standards, arguments etc.) in order to navigate socially, but we can try to reflect how and why we do this as we go along considering relevance and meaning in our personal conduct of life. Finally, acting ethically from a 1. person perspective, does not do away with the possibility of creating problems on a different level of human life. For example, sometimes personal ethical navigation with severe hereditary disease involves decision making and

1 A 1. person perspective refers to the perspective of the subject concerned. The term is borrowed from the rules of grammar and implies an "I", (Holzkamp 1985). acting with respect to procreation. With due consideration to the diversity of personal choices, this could be viewed as a kind of "eugenic" practice of our time on a societal level. A practice of judging lives more or less worthy, not argued with race and orchestrated by states, but argued with health and enacted by individuals. The business of judging and sometimes discarding of lives is probably inherent to humanity, but the way we think, argue and act in relation to it, should continuously be the focus of consideration. I shall return to this discussion in the concluding section of this article.

\section{Everyday conduct of life with Huntington's Disease}

t present, I am working on a project
to explore some of the practices and
technologies of medical genetics and their impact on the conduct of everyday life. In particular my study focuses on people at risk for Huntington's Disease (HD). This "at risk" population represents a new group of users in health care, not actually ill but at risk of becoming ill at a later stage of their lives. In medical terms HD is a neurodegenerative disease attacking the central nervous system. Symptoms involve involuntary movements of the entire body along with a specific form of dementia. HD has a mean onset of 35 to 45 years of age, but symptoms can become manifest at any age. Usually symptoms progress until death after 10-15 years, but longer periods of illness are not uncommon, some extending into very old age. As you might suspect, HD is amongst the severest of the known hereditary illnesses. There is, as yet, no known cure, no way of postponing the outbreak of symptoms or delaying their progress. In a few instances involuntary movements might be eased medically. Statistically $50 \%$ of the members of any affected family will inherit 
the mutation and hence develop the desease at some point. Put differently there is a $50 \%$ risk that any affected parent will pass on the desease to each of his or her children. If the HD mutation is not passed on to a child this person will not become ill and will not pass on the mutation to succeeding generations. The desease then stops in this branch of the family.

\section{Theoretical perspective and focus}

$\mathrm{I}$ my work the concepts of everyday conduct of life and personal trajectories of participation across contexts have become solid analytical tools. My way of thinking about "lives with HD" and the way I go about researching these lives is rooted in German Critical Psychology (Holzkamp 1985). In this line of theorising, the basic understanding of persons is not informed by an essence of personality or by traits, but informed by the way people conduct their everyday lives across contexts of social practice. Subjectivity and action are concepts basically indicating that we would not be the way we are if not in plural. They point to the related and active nature of humanity and suggest a way of understanding the connectedness of persons in society, which is neither functionalist nor structuralist. Social psychology has long been struggling with the analytical distinction of person/society and it has proven difficult to weave this distinction together into a more complex, relational and organic understanding. Critical Psychology makes this attempt by conceiving of persons as embedded in larger socio-historical and cultural practices, acting in ways that are both structuring and structured in concrete contexts of social practice. The plurality of contexts is a recent theoretical development suggested by Ole Dreier (1999). Dreier's point of departure is a particular critique of
Klaus Holzkamp's “Grundlegung der Psychologie", where persons are conceived as participants in social practice abstracted from the concrete myriad of contexts that constitutes everyday life. Dreier thus speaks of persons participating in multiple contexts, in varied but related ways. This transformation from the singular to the plural helps us understand how personal participation in one context is formed in part by how we participate in other contexts and how there may be differing ways of participating in differing contexts. These differing ways are related to our positions and perspectives, our possibilities and limitations, analysed as conditions, with meaning (for us), connected to our reasons (grounds) for doing things when going about living our lives.

\section{Contradictions}

n important concern of mine is to
understand how contradictions work
in people's everyday lives. In a
Critical Psychological framework contradictions can be viewed as an integral part of how people live and participate in ongoing social practices, as well as of how professional and societal practices work. This understanding is opposed to viewing contradictions as dysfunctions or failures in the art of living, as would be the case in some cognitivist, rationalist and dynamic traditions. Furthermore, the concept of participation is connected to an understanding of human development as an ongoing process where continuity and change are part of the life long struggle of being and becoming a certain kind of person. In other words we have to make an effort to maintain well established ways of life (routines) and to change in line with changing conditions, needs and interests. Practice refers both to how persons en-

2 "Foundations of Psychology", Campus Verlag, 1985. 
gage in living their everyday lives, but also to the professional practices that are there to serve us, and which we may or may not make use of. Furthermore practice refers to wider societal practices, such as the emergence of research strategies and priorities, the development of technologies and treatment regimes. Thus the term practice supports the project of weaving together the understanding of "persons in society", in as far as it prompts us to analyse how various practices come to play a part in people's lives. This is one of the points where the scope of my research fades out and I start looking in other directions for further elaboration of societal analysis to inform my work. The fields of sociology and medical anthropology have made useful contributions in this regard as they treat such questions in more detail (Novas \& Rose 2000, Mattingly 1998, Rapp 2000).

\section{Research approach}

I

am engaging in the field of investigation ad modum action research (Lewin 1948, Aargyris 1985, Whyte 1991, Jyrkämä 1996) or more specifically practice research in the Critical Psychological tradition. ${ }^{3}$ Practice research is a way of acknowledging the involvement of research in practice. Specifically the involvement of research in developing ways of thinking and going about dealing with people's lives in practice. Instead of trying to do away with the meaning of my research for the people that I interview, work with and others who have to accept me as a further aspect of the HD public arena, I try to understand and conduct my research in accordance with how I would like

3 Holzkamp 1983, 1985, 1994, Markard 1987, Osterkamp 1990, Fahl \& Markard 1992, 1993, Markard, Holzkamp \& Dreier 1994, Dreier 1993, 1996, Højholt 1993, Mørck 1995, Nissen 2000. to participate, contribute and make a difference. A way of making my mind up about such difficult questions is trying to stay focused on what moves the lives of persons living with $\mathrm{HD}$, their 1 . person perspectives. I also find this focus helpful with respect to not slipping unthinkingly into the problems, dilemmas and developments of professional practice. Problems of institutional practice sometimes draw our attention away from the fact that persons at risk of inherited disease face changing conditions and problems, so that professional practice has to change accordingly in order to stay relevant. One way of aiming at making changes relevant is paying close attention to the changing conditions and problems in people's everyday lives and to reflect in what ways professional practice can be of assistance to these persons.

\section{Why this focus?}

$\mathrm{P}$ sychological research into HD has mainly dealt with generating statistical accounts related to events taking place within a narrow proximity of the professionals working in the field. That is in relation to genetic counselling, genetic testing, reproductive technologies, diagnosing etc. In this line of research, people at risk are represented in the form of pre- and post morbid personalities or traits, coping skills and strategies, standard reactions to presymptomatic genetic testing etc. To my knowledge only a small percentage of the literature addresses the social and psychological concerns of people who live with HD. ${ }^{4}$ Therefore, it is my contention that psychological research at this point in time should be about how people live when at risk for HD, how they conduct their lives and what issues are of con-

\footnotetext{
4 There are important exceptions, some of which are: Nancy Wexler 1996, Cox \& McKellin 1999, Carlos Novas 2000, Claudia Downing (in prep).
} 
cern to them. The focus is thus not one of disease in and of itself, but of how, where and when disease becomes an important issue and how it is sometimes not an issue at all. It seems that the importance and place of HD changes over time, with changes in life conditions and shifts in what people are concerned with in their lives. It also changes along with what technologies and other professional assistance is "on offer" etc. This focus on how people conduct their lives and on their 1. person perspectives I find important and potentially useful with respect to 4 concerns. Firstly, understanding people struggling to live lives with HD - and other hereditary diseases. Secondly, informing professional practice and dealing with questions raised in such contexts. Third, informing research in the social sciences and related work. Fourth, informing political decision making. It is my hope to participate in the development of a theory that can potentially deal with all four of these aspects by hanging on to the personal perspectives of those at risk. Not in isolation, but in connection with the perspectives of those working in the field, researchers and policy makers.

\section{How to do research to stay loyal to this focus?}

$\mathrm{T}$

his is no easy task. Where do you start in order to end where? What do you include and what do you reasonably leave out? Below is a brief overview of my empirical material and the contexts in which it has been generated.

I started out by bringing together a small group of 5 persons with HD in their families and asked them to tell me what they thought were important issues in their lives and what they thought would be important to focus upon in a psychological research project. I still remember this first meeting, where a lot of things were told that I had not imagined prior to the meeting. The implications for family relations were especially striking. HD was portrayed not so much as an individual concern, but rather an issue involving the extended family. People did not tell me what "important issues" they could think of, but rather they told me their life stories. Stories about families that had to carry a special burden. Childhood with a father or mother gradually changing, loosing the grip, falling apart. Parents splitting up, uncertainty about "what was wrong", drinking problems. Then finally a diagnosis. The relief of knowing and then the realisation that other family members, grandmother, an uncle, had the same "thing" and that it might hit you, your brothers and sisters, your cousins. Some remaining unaffected. Like flipping a coin 50/50. The cruelty of this, the injustice. Visits to the nursing home, extended over years, the disease displaying all its horrors until finally your parent dies. Feelings of guilt about not visiting. The inability to face your parent utterly helpless, knowing you might end up the same way. Feelings of letting an ex-wife or ex-husband down, too much water under the bridge. Glimpses of hope for your own future, the future of your children. Enhanced feelings of responsibility and duty to know. Such were these first stories. To me they were overwhelming. I did not take many notes during the meeting, but wrote extensively afterwards. Along with meeting these 5 individuals I also began to participate in counselling sessions. Gradually I have become an active part of the sessions, although the final professional responsibility has always rested with the medical geneticist. I do not write down notes during these sessions, as counselling is not a point of focus in itself, but I do write down my reflections on the role and importance of counselling in people's lives as a whole. Another valuable source of information has been staff meetings (and lunches) at the genetics de- 
partment. Here I found a world of its own, completely foreign to me. I did not understand most of what they talked about in the beginning, but gradually became familiar with some of the terminology. Then, of course, I have conducted interviews. Interviews have preferably taken place in people's homes, when possible. I quickly learned that meeting people at the medical faculty, where they might have come for counselling on a previous occasion, was not a good idea. Meeting in these surroundings made it even more difficult to convince people that I was really interested in their everyday lives and not just in the aspects concerning disease. Usually I saw interviewees on their own but on two occasions I have had the opportunity to speak with married couples. I carried out 18 interviews with people at risk, some tested and some not, and 2 with professionals working with HD. Finally I have been lucky enough to be invited to participate during weekends for healthy, at risk or tested individuals and their spouses or friends. On these, and similar occasions like the annual general assembly of the National HD Association, I have taken field notes in the broad, anthropological sense of the term. Another line of my work, which has developed rather slowly, is my engagement in various research communities that are of relevance. Amongst others, I would like to mention the importance of exchanging notes and having discussions with the sociologist Carlos Novas, who is also working on issues related to HD. Starting his empirical work in places of social importance, such as chat rooms on the internet, rather than everyday life, he moves towards an understanding of what and how societal conditions and developments matter in people's everyday lives. Such analysis are necessary in order to add sociological substance to our understanding of the relatedness of "persons in society". Another source of inspiration is the work of Mette Nordahl Svendsen, a Danish anthropologist, looking into cancer genetic counselling. The empirical focus of this research project is on user perspectives on counselling, testing and genetic information with respect to understanding more about the impact of the new genetics on people's ways of thinking about and conducting themselves. This is an important study in relation to my own for several reasons. Firstly, the empirical approach resembles mine, and secondly, the diseases under scrutiny are somewhat different, both regarding geno- and phenotypes and especially with regard to possibilities for treatment. It is striking that in comparing notes, we find parallel issues being at stake in people's lives, but their importance and meaning differ. This is expressed in ways people live, think and speak about themselves in relation to disease, how they make decisions and reason about them.

To sum up, trying to stay loyal to my focus involves, meeting people at risk in differing contexts, at differing points in their lives, with differing family histories and current life circumstances and a differing outlook on the issues and concerns in lives with HD. And it involves meeting professionals, researchers and various activists the same way. That is, in differing contexts, participating in changing ways, with differing goals and aims, working conditions, educational background etc. In this way I am aiming at pursuing themes of importance for the way persons at risk conduct their lives. Taking a practice research approach, I also draw on principles of anthropological field work. This means that I am doing as much participant observation as time and opportunity allow me, in order to generate other qualitative materials apart from the transcriptsof interviews. This should allow a broader view of what people at risk deem relevant and the ways they go about living, in relation to relevant conditions for doing so. 
What is included by this focus?

$\mathrm{B}$ y trying to stay loyal to my project about getting as close as I can to people's reasons and ways of doing things, I hope that I can avoid the personalising tendency of essentialist personality and traits approaches. To me this means avoiding the tendency to develop theory that is most likely to be used to hold people personally responsible and personally to blame for whatever life circumstances they have arrived at (Osterkamp 2000) and thus not understanding their subjective reasons and perspectives. I also hope to keep my own moral convictions at a manageable level. In other words, I have set myself the task of trying to stay humble in order to understand what the other person understands, as Kierkegaard has put it. Not that I intend to go all soft and uncritical on my material and the people I develop personal relationships with (that would not do them any good anyway), but in order to do them and their ways of life justice by framing the understanding of their lives in a broader socio-historical and cultural perspective. This focus provides me with a frame for thinking about subjective conditions, meanings and reasons in lives with severe, disabling and deadly familial disease. It has opened my eyes to the fact that all of this becomes important or finds a place in peoples lives in differing ways, at differing times, for various reasons and sometimes not at all. A point in case would be the fact that $10-12 \%$ of people living at risk take the genetic test to establish whether or not they will become ill at some point in their lives. Talking to people in differing life circumstances, at different ages it becomes apparent that there is much more involved in taking the test than the need to know, responsibility towards offspring, planning the future etc. There is a lifetime of experiences with or without the knowledge of HD being in the family. People tell different stories about what has been of importance, how and when, before they arrived at actually going through with testing. The same can be said about people who have not (yet) been tested, but are aware of the possibility.

\section{Deciding where to look and what to look for}

I $t$ is striking that the key concepts I was confronted with when I rather ignorantly, started exploring this field were concepts such as late onset disease, risk and testing. Not the concepts of everyday conduct of life or personal trajectories of participation across contexts. The former concepts have emerged from the field of medical genetics and the latter from Critical Psychology (leaning on sociological and anthropological traditions) trying to understand people in their "everyday lives" (Holzkamp 1998, Dreier 1999, Osterkamp 2000, Bech-Jørgensen 1994). Immediately apparent have also been issues of responsibility and decision making in lives with HD, and the distribution of responsibility for health and healthy conduct between "persons at risk", important others and professionals. These issues become apparent in counselling and clinics because these are important sites for negotiating and distributing responsibility amongst the involved parties. This is reflected in the movement of theoretical discussions of counselling from "eugenic advice" in the 1920s and 1930s, towards "non-directive counselling" in the 1970s, and then "shared decision making" during the 1990s (Elwyn et al 2000, Novas 2000, working paper), which marks the changing demands professionals place on users of health technology (Dawning, in prep). Counselling and clinics are important sites for situating genetic knowledge in order to be useful to per- 
sons living at risk and important sites for establishing what counts as scientific knowledge and what is relegated to the personal realm of belief (Byron Good 1994). Professional practice in this field can therefore be scrutinised as supporting a certain kind of "technology of the self", borrowing a term from Michel Foucault (1990), taken up by Nicholas Rose (1998), meaning a certain foundation for thinking about and conducting the self. As I see it, the "technology of the self" offered in the contexts of genetic counselling and clinics is based on the idea of autonomous, informed, rational, and responsible decision-making individuals. It is therefore a self-technology that emphasises individual decision making and responsibility while downplaying the wider familial, social and societal inter-relatedness. It privileges the logic of genetics almost to the exclusion of other logics (Duster 1990, Mol and Berg 1994). For example, the genetic logic is of such primacy in counselling, that I did not notice it myself, until I encountered a person at risk for HD who disputed medical genetics as the fundamental understanding of the disease. This has only happened once during all my encounters with persons at risk, marking a difference from the multitude of lay understandings of for example tuberculosis and cancer (Sontag 1991, Otto 1994, Forchhammer 1996, Bowker \& Star 1999).

I shall develop this argument further, but first I would like to ascertain that I am not opposed to genetic research, counselling or the new genetic technologies as such. Rather I am highly critical and at times quite uneasy with it. Nevertheless, I participate in counselling sessions, I recommend people to see counsellors or therapists for various reasons and I do not think anybody should go through with testing for HD without having talked to someone who knows about living life with a test result. We have invented technologies (psy technologies included) to show people "who they are" genetically, their ways of thinking, feeling and acting and we are thus obliged to participate in the enterprise of inventing social technologies dedicated to assist the conduct of lives with what people have learnt. Furthermore, we are obliged to make extensive efforts to come to grips with what this means in a long term perspective. We might be in the process of establishing practices that are unproblematic on an individual level, but taken together bring about an unwanted societal directionality. This includes bringing about fundamental changes in human genetic material or supporting eugenic practices. It seems a likely proposition that "we", taken as powerful citizens, scientists and states, cannot be entirely in control of such directionality, but we are not entirely without means of influence either. We are changing possibilities and constraints as we develop genetic research and practice and we should therefore, as a moral ideal, give long term directionality some thought.

\section{Technology becoming part of my research}

$\mathrm{D}$ efining the framework of my research as everyday life with HD, I unexpectedly came across an extensive use of specific technologies in medical practice dealing with HD. Interestingly, I did not have a technological focus or even an awareness of the importance of technology for people living at risk of HD when I first started in 1998. But as time passes I see myself increasingly having to study the technologies which are in use, as well as in the making, when researching life at risk for HD. Firstly, the actual development of research on medical genetics and the development of technologies, tools and medical procedures to match the new findings has sped up considerably over the last few years. 
Outlines-2001-1. qxd 19-06-01 13:31 Side 43

OUTLINES • No. $1 \bullet 2001$

Genetic research as we know it has only been carried out for approximately two decades but is developing rapidly (Huntington's Disease, A Guide for Families ${ }^{5}$ ). Secondly, persons living at risk of any genetically based disorders only gradually make use of the technologies that become available. Actual procedures for offering genetic technologies to at risk individuals have to be developed and accepted as possibilities by users before they become part of the health care regime and offered as standard procedures (Foucault 1987). Nevertheless, in my experience whatever technologies are made available will get used and will eventually become accepted as standard procedure. Consider for instance IVF, which was met with strong opposition when it was first introduced less than two decades ago, but is now a standard "medical" procedure in most modern societies.

\section{Changes in technology as conditions for responsibility and choice}

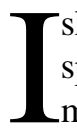
shall now turn to the questions of responsibility and choice. The development within medical genetics that I have just spoken of, can be described as taking place in multiple contexts, enacted by subjects with varying interests and positions (Latour 1999, Dreier 1993). In this sense it can also be described as only partially or regionally orchestrated. One of the implications is that medical knowledge and technology change in not entirely foreseeable ways and thus conditions for choice in everyday conduct of life change in ways that are equally difficult to predict. Persons at risk plan their futures with access to the present possibilities and constraints, but without knowing how these will change (Ettorre

5 www.discoveryhealth.com/DH/ihtPrint/WSDS.../ 33290.html?d=dmtContent $\& \mathrm{k}=$ basePrin
1999). A brief view of the recent history of genetic testing will serve to illustrate this point. Let me sketch out a few of the important changes in the technology, which in turn has changed deliberation on responsibility and choice in peoples lives with HD as well as in professional practice.

\section{History of HD related technology}

B efore the discovery of the HD mutation, linkage analysis was carried out for some years. This was done partly as a research effort to locate the mutation, and partly as an offer to persons at risk of knowing their "genetic status". Unfortunately, linkage analysis was not always conclusive. For instance if key family members were not available or unwilling to donate a blood sample, or for technical reasons. The actual mutation coding for HD was discovered in 1993 after more than 10 years of intensive research (Wexler 1996). This was considered an encouragement, in as much as it indicated that genetic research was progressing towards a more encompassing understanding of HD and hopefully a cure. Shortly after the discovery of the mutation testing became general practice throughout the western world and a set of international guidelines of "how to do it" were worked out. In the mid-1990s the first prenatal diagnosis was carried out in Denmark, amounting to a total of 42 today. In 1999 the first attempts at using pre-implantation diagnosis along with IVF were initiated.

\section{Knowledge as situated}

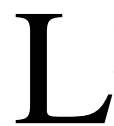
ooking at these developments and the changing conditions it offers to persons at risk, it becomes very hard to speak of well informed, ethically right and responsible choices in universal terms. This 
is true for both persons living at risk and professionals researching and practising within the field. The fast and regionally orchestrated development draws into question our conceptions of knowledge and informed decision making. How can we be well informed, or pass on solid information if the information and associated technologies are constantly revised? And how then, can decisions be uniformly ethical? What about the claim that so called universal and solid genetic knowledge is ruled by different explanations, logics and practices (Mol \& Berg 1994)? As in the different practices of genetic science and counselling, science being a practice concerned with the production of solid facts and counselling being a practice where genetic knowledge is situated and negotiated by professionals in relation to persons at risk? (Rapp 1988/1995). And what about the uncertainties and ambiguities that appear when taking a close and detailed look at where genetic research stands today?

\section{Knowledge in social practice}

$\mathrm{D}$ oing field work I have found that people refer to different kinds of knowledge with respect to HD. There is "right and wrong" knowledge, "to much and to little" knowledge according to contexts and participants. Furthermore, in counselling certain kinds of knowledge are promoted as scientific, whereas other kinds are relegated to the realm of belief. The first kind is enacted as "right", the second kind as "wrong" knowledge (Good 1999). Both professionals and persons at risk participate in establishing borders between knowledge and belief. As mentioned previously, I have encountered one single person at risk who relied more on his own version of his situation than on medical knowledge. Differences in what is deemed "right" or "relevant" knowledge are also expressed in the fact that I ask other questions and talk of other subjects, in the context of counselling, than the medical geneticist. The medical geneticist tend to concentrate more on the family history of disease and on passing on relevant information about disease related issues as well as on consequences for everyday life. I tend to concentrate more on what all of this means to people, their concerns, their way of dealing with everyday life and how it makes them feel here and now. Both of us ask and talk in relation to the reasons persons state for coming for counselling, what they know in advance, what they say they want to know more about or want to discuss. We think of "right" or "relevant" knowledge in differing ways because our understanding of what is at stake in people's lives and what should be of concern in the counselling session differ. When persons at risk go home, when I go to take notes on my laptop and the geneticist speaks to his dictaphone, knowledge is situated again into a new context with other participants, interests and obligations. Whether knowledge is situated as "right or wrong" depends on the degree of detail, the theoretical foundations and the perspective taken. Several kinds of HD get enacted in counselling sessions, at home, in clinics and doing research (Mol \& Berg 1994). Taking a historical perspective "right and wrong" has also developed over time, changing the emphasis and concerns of geneticists and counsellors (Novas, working paper). It thus makes more sense to redefine knowledge as heterogeneous and transformable, partial and negotiable with respect to context, participants and interests, as well as to maintain that knowledge is always related in one way or another to a perceived materiality. Furthermore, I would argue that having differing professional perspectives represented is one way professionals might widen the scope of the issues addressed and handled in counselling. If such differences are reflected and 
discussed amongst professionals, this could potentially become a resource for the persons seeking counsel.

\section{Making decisions and living them}

$\mathrm{T}$

The next issue of concern is that of making and living decisions. It is obvious that couples making use of preimplantation technology have to engage in some sort of conscious decision making in order to arrive at actions that involve their social lives, bodies and that have serious consequences for a lifetime. But there is something about the idea of conscious decision making that makes me uneasy (Sloan 1996, Dawning in prep). Firstly, conscious decision making implies a process of rational cognitive as well as discursive activity and secondly, the term implies a corresponding relationship between deliberation and action as central to understanding how we conduct our lives. And this is not how I would characterise the way people go about living with $\mathrm{HD}$ in general. That is not how I would characterise the way anybody goes about living in general. We do not think and talk every aspect of our lives and we do not do it in ways that correspond uniformly to our actions. So even though I think it makes sense to talk about choices to indicate differences that make a difference I also think that we make more or less explicit decisions all the time as we go along. Everyday life involves deliberation, decision making, acting, but in round about ways. When something becomes important or pressing enough we make explicit decisions about them. We might even voice these decisions. But we do not necessarily carry decisions out at once or at all. And they may not be rational from all perspectives. There may be obstacles to a chosen course of action and we might end up not being able to live according to our decisions. We constant- ly revise our plans, change our minds, do differently than intended in accordance with the complexity of daily living. People at risk tell me about how they made the decision about having the test long before going through with it, or how they know they will have the test sometime in the future, but not exactly when. Sometimes other issues have to be settled and lived through first. I have been told more than once that the death of an affected parent or near relative "made the time right".

\section{A problem in making and living ethical and responsible decisions}

I shall now move on to illustrate that the fast, regionally orchestrated development along with the situated, uncertain and ambiguous nature of knowledge draws into question the idea of setting up universal ethical standards for decent human conduct with HD. Ethics and responsible decision making understood as universals, also have a very hard time dealing with the complexity and contradictions of lived life. Taking the notion of contradictions seriously, it follows that there will always be aspects of everyday conduct which does not fit into a general ethical framework (Rose 1999, Novas \& Rose 2000, Callon \& Rabeharisoa 1999). This is not to say that we either could nor should refrain from having ethical standards, just that we have to think and argue differently about them. I shall elaborate this further throughout the rest of the article.

\footnotetext{
6 Some persons at risk, people that I talk to about my project in general and quite a few social or health professionals express the view that certain specific obligations for ethical and responsible behaviour rests with persons at risk of severe hereditary diseases, in particular with respect to having children, informing relatives and potential partners.
} 
It is a general reaction ${ }^{6}$ that persons with HD in the family should have moral reason to reflect extensively on their lives and the decisions they make. This is because HD has serious implications for children, spouses and other family members too, as they often participate in the care of the ill. But far from everybody does reflect life in such a way (Callon \& Rabeharisoa 1999). In this respect persons at risk of $\mathrm{HD}$ are no different from the rest of us. Based on the extensive contact I have had with persons at risk, I find it probable that reflections of how to go about living and deciding is just as widespread for persons living with $\mathrm{HD}$, as with any other serious health concern, and perhaps even in people's lives in general. I would like to support my argument with some statistics. Presently, there are approximately 1300 persons living at risk for HD in Denmark, and a further 250 persons are ill with the disease. How many of these can be said to be active in the public arenas of HD? There are 675 members of the national HD association (including at risk or ill individuals, families, relatives, nursing homes, medical doctors), 300 pre-symptomatic tests have been carried out so far, and 42 prenatal diagnosis in 30 couples (11 at risk women, 19 at risk men). Between 20-40 persons participate at summer camp for the ill and their care-givers each year (quite a few participate year after year), and between 20-30 persons participate in weekend seminars for young persons at risk and their partners. Considering that most active persons are active in more than one context, I find it unlikely that more than 25 $\%$ of persons at risk could be active on any of the public arenas of HD. For obvious reasons, I seldom engage in contact with those who are not active. I hear about them from family members and friends. They are often

7 The numbers are drawn from the HD register at the Department for Medical Genetics, at Copenhagen University. talked about by those who are "active" as "refusing to face the facts", "not able to cope with it", "ignoring problems", or even "repressing their situation" in the Freudian sense. Such differences in approach often pose difficulties for relationships.

\section{Acting on the public arenas of HD - acting in everyday \\ life}

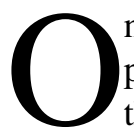

$\mathrm{n}$ that note I find it interesting that persons at risk apparently confront themselves with knowledge and awareness of HD (or other serious health concerns) in various ways, as do the rest of us. Action possibilities include not doing anything in particular, dealing with disease related issues as they occur in everyday practice, settling for whatever the family passes around as common knowledge, pursuing information in other places, checking the internet, joining activist groups, taking out life insurance, requesting counselling, having the genetic test, going for a prenatal diagnosis, caring for family members. All of this involves some kind of deliberation, decision making and action. Some persons at risk claim they have decided to have the test, but do not actually pick up the phone and make an appointment for a long while. Doing so would be extending the decision into corresponding action. But it may be that instead of this particular action a new decision is made not to have the test. Nevertheless, I would argue that the first decision is a decision all the same. This means that we can not claim that decisions we have only reasoned about has to be backed up with corresponding action or vice versa. Instead we might say that decision making involves more or less explicit reflection, as well as action (in correspondence or opposition to reflections) situated in the practicalities of everyday life. 


\section{Responsibility and} knowledge

$\mathrm{F}$ lollowing this argument, there are many ways of conducting everyday life, many ways of making "responsible choices". Awareness of possible implications is but one aspect, emotional responses to life circumstances, possibilities and constraints of everyday life, the interests and needs of a partner or family, are other aspects that come into play (Cox 1999, Downing, in prep).

If you accept this way of understanding decision making, it has implications for how we argue about responsibility. Firstly, the ones not actively seeking out information or knowledge on the disease and living as if no such thing was at stake in their lives can not generally be categorised as irresponsible, nor defensive or repressing. I am not saying that this may not be an acceptable moral judgement in a particular situation, just warning against equalling one with the other. Actually, it seems rather difficult to avoid knowing something about what is at stake if people have the slightest awareness of HD being in the family. ${ }^{8}$ Ways of dealing with and reasoning about the disease is usually part of life through contact with family, however limited this contact may be. Equally, the solid media concern with genetic diseases makes it very difficult to maintain an entirely ignorant position. That it is indeed difficult to avoid the subject completely is confirmed by my contact with people at risk. Although some family members characterise others as "refusing to deal with HD", they still do not appear to refuse or shut the matter out entirely. Rather, they go about dealing

8 Some people simply do not know about being at risk, for example if the disease has never been adressed or diagnosed in any family member, if they are adopted or for other reasons have no knowledge about one or both of their biological parents. with HD in less explicit ways, perhaps thinking to themselves and talking to one or two people close to them. They deal with disease related issues when concrete situations arise, for example when considering having children or when actually pregnant, when starting a relationship, making business investments etc. Talking to me may be one of the first steps into the broader public arenas of HD recognised by others as such. Secondly, we should not think of persons at risk as having to engage in any more conscious and responsible decision making than the rest of us. Why should there be ethical and normative demands put on some people, that for one cannot be met by means of genetic knowledge and technology, and secondly are far more demanding than the ethical and normative demands put on the rest of us? I have a young child myself but do not have a life insurance and rarely remember to put on my bicycle helmet. No one flinches an eyelid. Well, maybe a few, but they are not backed up by an array of public arenas to say what is morally right. On a societal level, it seems that an implication of establishing severe health risk is creating a public arena whereby some people are subjected to a moral logic defined to a large extent by others who are not themselves at risk. Entering the public arena means embarking on the entire package of deliberations, choices and actions that follows from this logic. Soon people living at risk have to justify what is staged as a "personal choice" publicly (Callon \& Rabeharisoa 1999, Strathern 2000).

\section{Guilty as charged}

I would argue that living life involves deciding in some sense, in as much as living one way facilitates and excludes certain other ways, doing this today, outlines the possibilities and constraints of tomorrow. Living without persuing what "that funny 
family thing" might be, carries the potential for "business as usual" as well as for great pain. Likewise entering the public arenas of genetic knowledge, technologies and testing carries the potential for "deciding and justifying with a view to the future" as well as despair when trapped by its limits. And if we look at ways HD gets to play a part in people's lives there is a further argument against equalling ignorance with acting irresponsibly. In certain families symptoms typically come about at a late age, some afflicted members dying for other reasons before the onset of HD related symptoms. HD may not always be diagnosed and if so the full range of consequences may not become solid knowledge for some time (see Wexler 1996). ${ }^{9}$ In some families HD is indeed common knowledge, but it is equally difficult to maintain a general judgement when you consider the arguments about how knowledge, technology, counselling, decision making are situated and related parts in complex social practice. What kind of knowledge, what degree of detail, how closely should scientific developments be followed for persons at risk to be sure that they have the foundation to conduct themselves in a morally impeccable manner? On the other hand, if you enter the realm of knowing, the public space of genetics, counselling and activist groups, you can be certain that there will be others there wanting to help, but also wanting to set standards, put you to the test and disapprove of actions.

9 Alice Wexler describes how she herself and her immediate family only very gradually, due to various circumstances, come to recognise that her mother is suffering from HD. She is mid-twenties before a final diagnosis is made and theoretically could have had children by then.

\section{Further reflections on personal conduct and social practice}

$\mathrm{S}$ umming up: Medical genetics is continuously bringing about knowledge while its associated technologies offer new choices between different courses of action. Taken as a whole the public arenas of HD can be said to prompt persons living at risk to reflect on their situation and to act in moral accordance with what they know. Following this understanding ignorance can be staged as problematic in as far as it limits persons at risk in acting responsibly, for example towards family and offspring. To put it differently, you have to make use of genetic knowledge and technology in order to be living and choosing responsibly. But if we question the notion of knowledge and technology as true and fixed and show that these are not beyond uncertainty, ambiguity and negotiation when used as a basis for responsible decision making, the demand does not seem entirely justified. The fast changing and situated nature of knowledge and technology makes it difficult to maintain that entering the domain of "knowing" assures responsible decision making in a universal or absolute manner (Rabinow 1996). The same way ignorance can not be judged irresponsible per se. The notion of informed decision making can be problematised as staging a moral or ethical demand that neither genetic testing, associated reproductive technologies makes it possible to live up to. Nor does living in and of itself, if we take life to be both complex and contradictory. Furthermore, the way responsibility and decision making is enacted by people at risk, their families, research and clinical communities, are shaped by contemporary western notions of autonomy, individuality and authenticity (Taylor 1991). In my view the modern movement towards a certain kind of autonomy adds an- 
other piece to the puzzle of understanding how individuals are responsibilised. We are commonly met with the "duty to be healthy" along with the "duty to know". We even have to think, feel and act in accordance with such moral demands in order to establish ourselves as responsible decision makers. Which then becomes a further "duty". These are powerful "technologies of the self" in our time, and certainly within the public arenas of HD. But they are not the only ones. The notions of autonomy and authenticity also carries notions of respect for the individual and his or her choices.

To finish off, I would like to make sure that my line of argument is not taken as antimoralist, or relativist in the sense that anything goes out of respect for individual autonomy. Understanding what moves people from a 1. person perspective and supporting their autonomous decision making in counselling does not exclude arguing about morality or ethics. I cannot develop the argument in detail here, but I would like to give an indication of where it is headed. Firstly, the notions of autonomy and authenticity themselves rest in part on a moral ideal, they have emerged historically and are bound up in striving for better ways of living. Leaving it up to the individual is a particular enactment of the notions of autonomy and authenticity, which does not save us from discussing what might be the better way of enacting them (Taylor 1991). Secondly, neither autonomy nor authenticity automatically exclude the notion that we are interrelated with other individuals. If we are indeed to be understood as socially embedded, it follows that we live our lives in social relations (Holzkamp 1983). In other words, autonomy does not have to be based on the notion of the free floating individual, but might be seen as bound up with the right to expect and exercise equality and democracy. If we are dialogical beings, as Charles Taylor claims, we depend upon each other in order to be authentic (1991). And if we are characterised by mutuality on a fundamental level, it follows that we must understand ourselves as autonomous in the plural (Costall 1995).

Following this argument we are given the possibility to consider the wider familiar, social and societal implications of the personal conduct of life. We can do so without necessarily having to argue against the ideas of autonomy and responsibility. We may apply these considerations to the decision making of at risk individuals, researchers, professionals and policy makers alike. For example to the decision making with regard to living at risk, doing research and the possibility for recasting eugenic practices on a individual level. I feel obliged as well as compelled to touch on this discussion, because my area of research is irreparably bound up in deciding and acting on life and death. I am conceiving here of a kind of eugenics not as based on a hierarchy of races and enacted through discriminatory practices of governments, but as based on hierarchies of health and normality of bodily functioning and the decision making of individuals. The eugenic as well as anti-eugenic practices of our time are politically programmed in subtle but potentially powerful ways, enacted by persons living everyday lives in complex social practices. Because of the room for active anti-eugenic practices it is not as scary as its predecessor. Diversity of life is actually valued in a way that would have been out of the question in the 1920s and 30s. But still, one of the basic principles of eugenics is to make judgements on the worthiness of life on the grounds of genetic assumptions. As a minimum, such judgements of worthiness, be it with reference to racial purity, individual health, quality of life or cultural preference have to be qualified and discussed as matters of where we want to take ourselves and how this can be done in concretely lived lives of the 
people concerned. At least this seems a promising way of discussing such difficult issues, if we do not wish to leave it entirely up to one or the other standardised preferences or to individual decision making. If we accept judgements of the worthiness of life to be eugenic, in as far as it allows the classification and dismissal of lives, I think it sets the stage for a heightened awareness of our standards for what is deemed worthy, healthy and normal enough lives to be lived. More importantly, it enables us to discuss such standards. As medical genetics increasingly become part of lay-knowledge and offer new forms of technological assistance, this kind of awareness and discussion becomes progressively more necessary. This way, we may inform our decision making with discussions of the desirability of consequences in a wider context.

\section{Bibliography}

Argyris, Chris (1985): Action science, JosseyBass, San Francisco.

Bowker, G. \& Star, S.L. (1999): Sorting Things Out. Classification and its Consequences, The MIT Press.

Callon, M. \& Rabeharisoa, V. (1999): Gino's lesson on Humanity, conference paper.

Cox, S. \& McKellin, W. (1999): "There's this thing in our family: Predictive testing and the construction of risk for Huntington Disease", in Conrad \& Gabe (eds.): Sociological Perspectives on the New Genetics, Blackwell Publishers.

Downing, Claudia (in prep): Ph.D. thesis.

Dreier, Ole (1993): Psykosocial behandling, Dansk psykologisk Forlag.

Dreier, Ole (1996): “ÆEndring af professionel praksis på sundhedsområdet gennem praksisforskning”, in Jensen, Qvesel \& Andersen (red.) Forskelle og forandring - bidrag til humanistisk sundhedsforskning, Philosophia.
Dreier, Ole (1999): "Personal Trajectories of Participation across Contexts of Social Practice", OUTLINES, vol.1, pp5-32, DpF.

Duster, Troy (1990): Backdoor to eugenics, Routledge.

Elwyn, G., Gray, J. \& Clarke, A. (2000): "Shared decision making and non-directiveness in genetic counselling", Journal of medical genetics, 37(2): 135-138.

Ettorre, Elizabeth (1999): "Experts as "storytellers' in reproductive genetics: exploring key issues", in Conrad \& Gabe (eds.) Sociological Perspectives on the New Genetics, Blackwell Publishers.

Fahl, R. \& Markard, M. (1992): "Zur Forschungspraxis der Praxisforschung", in Benetka et al (red.) Gegen-Teile. Gemeinsamkeiten und Differenzen einer kritischen Psychologie 173-185. Profil, Munchen.

Fahl, R. \& Markard, M. (1993): "Das Projekt "Analyse psychologischer Praxis" oder: Der Versuch der Verbindung von Praxisforschung und Psychologiekritik", Forum Kritische Psychologie 32, Argument-Verlag.

Forchhammer, Hysse B. (1996): "Livskvalitet et nyt sundhedsbegreb?", in Jensen, Qvesel \& Andersen, Forskelle og Forandring bidrag til humanistisk sundhedsforskning, Philosophia.

Foucault, Michel (1987): Sexualitetens historie I. Viljen til viden, Rhodos.

Foucault, Michel (1990): The Hermeneutic of the Subject, Reitzels Forlag.

Good, Byron J. (1994): Medicine, Rationality and Experience: an Anthropological Perspective, Cambridge University Press.

Holzkamp, Klaus (1993): Grundlegung der Psychologie, Campus Verlag.

Holzkamp, Klaus (1995): "Selbsterfahrung und wissenschaftliche Objektivität: Unaufhebbarer Wiederspruch?", in Braun \& Holzkamp (red.) Subjektivität als Problem psychologischer Methodik.

Holzkamp, Klaus (1994): “Am Problem vorbei. Zusammenheitsblindheit der Variablenpsychologie", Forum Kritische Psychologie 28, 5-19.

Holzkamp, Klaus (1998): "Daglig livsførelse som subjektvidenskabeligt grundbegreb", UDKAST, nr.2, pp3-32, DpF. 
Højholt, Charlotte (1993): Brugerperspektiver. Foraldres, laereres og psykologers erfaringer med psykosocialt arbejde, Dansk psykologisk Forlag.

Jyrkämä, Jyrki (1996): "Action Research and Social Practices - new remarks on an old approach", Nordiske Udkast, nr.2, p33-44, DpF.

Kinsman, Gary (1996): “'Responsibility' as a strategy of governance: regulating people living with AIDS and lesbians and gay men in Ontario", Economy and Society 25(3): 393409.

Latour, Bruno (1999): Pandoras hope - essays on the reality of science studies, Harvard Universtiy Press.

Lewin, Kurt (1948): Resolving Social Conflicts. Selected Papers on Group Dynamics, Harper and Brothers Publishers, New York.

Markard, Morus (1987): "Kategorien, Theorien Empirie in subjektwissenschaftlicher Forschung", in Zum Verhältnis von Theorie und Praxis in der Psychologie, Bericht von der 4. Internationalen Ferienuniversität Kritische Psychologie, VA \& G.

Markard, Holzkamp \& Dreier (1994): Praksisportrat. En guide til analyse af psykologpraksis, unpublished manuscript.

Mattingly, Cheryl (1998): Healing dramas and clinical plots. The narrative structure of experience, Cambridge University Press.

Moll, A. \& Berg, M. (1994): "Principles and Practices of Medicine: The Co-existence of Various Anemias", Culture, Medicine and Psychiatry, 18:247-265.

Mørck, Line Lerche (1995): "Praksisforskning som metode, teori og praksis", in UDKAST no.1, 34-78.

Nissen, Morten (2000): "Practice research: critical psychology in and through practices", in Goodley \& Parker, Annual Review of Critical Psychgology, Action Research, Vol.2. 145181.
Novas, Carlos \& Rose, Nikolas (2000): "Genetic Risk and the Birth of the Somatic Individual", to appear in: O’Mally (Ed.): Configurations of Risk, Economy and Society (29/4: November 2000).

Osterkamp, Ute (1990): “Intersubjektivität und Parteinahme: Probleme subjektwissenschaftlicher Forschung", in Subjektivität und Politik, Bericht von der 5. Internationalen Ferienuniversität Kritische Psychologie, Verlag Arbeit und Gesellschaft Gmbh.

Osterkamp, Ute (2000): "Livsførelse som subjektvidenskabelig problematik", UDKAST, nr. 1, 5-28.

Otto, Lene (1994): "Et robust helbred eller et lykkeligt liv", i Jensen \& Andersen (red.) Sundhedsbegreber, filosofi og praksis, Philosophia.

Rabinow, Poul (1996): Essays on the anthropology of reason, Princeton NJ: Princeton University Press.

Rapp, Rayna (2000): Testing Women, Testing the Fetus. The Social Impact of Amniocentesis in America, Routledge.

Rose, Nikolas (1998): Inventing our selves. Psychology, Power, Personhood, Cambridge University Press.

Sloan, Tod (1996): Life Choises. Understanding dilemmas and decisions, Westview.

Sontag, Susan (1991): Illness as metaphor. Aids and its metaphors, Penguin Books.

Strathern, Marilyn (2000): Abstraction: a practical problem, conference paper.

Taylor, Charles (1991): The Ethics of Authenticity, Harvard University Press.

Wexler, Alice (1996): Mapping Fate. A memoir of family, risk, and genetic research, University of California Press.

Whyte, William F. et al (1991): Participatory action research. Through Practice to Science in Social Research, Sage, London. 